\title{
La economía del don le responde al modelo en crisis del homo oconomicus ${ }^{1}$
}

The economy of the gift responds to the model in crisis of homo oeconomicus

Paola Delbosco Profesora del Instituto de Ciencias para la Familia Universidad Austral, Buenos Aires, Argentina

\section{Resumen}

Las crisis externas e internas que perturban la vida de las personas, las naciones y las regiones de nuestro mundo nos instan a buscar modelos que superen al del homo oeconomicus. El mundo del trabajo, estructurado sobre la base de la productividad de un individuo abstractamente autosuficiente, se muestra absolutamente inadecuado para la vida de las personas y para la formación de las familias. El individualismo está debilitando los lazos sociales y la economía necesita del tejido social para subsistir. La economía del don ofrece un enfoque diferente, cuyo fundamento es la reciprocidad, en un dinamismo caracterizado por la cooperación y la generosidad. Esta peculiar actitud no impide resultados económicos positivos, pero en el desarrollo de una comunidad incluye otros aspectos, como la aptitud para formar una familia funcional y la cohesión social. Confirma esto una investigación del Centro Conciliación Familia y Empresa del $\mathrm{IAE}^{2}$ entre más de 800 directivos de empresa, varones y mujeres, y mandos medios en la Argentina, que muestra que las personas que a través de su trabajo buscan constantemente aportar al bien de los demás, poniéndose en línea con los criterios de la economía del don, son también quienes armonizan profesión y familia. Es así que la importancia de la familia es confirmada una vez más en estudios empíricos.

1 Trabajo presentado en el marco de CONFyE, IAE Business School. Universidad Austral. Buenos Aires. 2016. 2 Trabajo de campo "El balance de la vida laboral-personal en los directivos de empresa, Argentina 2013", analizado en Guillermo Fraile: ¿Por qué trabajas tanto? Buenos Aires, 2017, editorial Mil Palabras, cap. 4. 
Palabras clave: economía del don, homo œconomicus, self interest, reciprocidad, gratuidad, familia, motivación trascendente.

\begin{abstract}
The negative impact of external and internal crises on people's lives, nations and regions of the world urges us to find models that overcome the Homo oeconomicus model. The world of work, structured on the basis of productivity of an abstractly self-sufficient individual, is absolutely inadequate for people's lives and family foundation. Individualism is weakening social bonds but economy needs social context to survive. Civil economy offers a different approach, founded on reciprocity, in a dynamism characterized by cooperation and generosity. This peculiar attitude does not prevent positive economic results; in addition, it includes the development of other aspects of a community, such as the aptitude to create a functional family and social cohesion. The aforementioned was confirmed by a research conduct by IAE's Family and Business Conciliation Center. Its sample was more than 800 men and women occupying manager and CEO positions in Argentina. Its results showed the people who constantly seek to contribute to others through their work, putting themselves in line with the criteria of civil economy, enjoy a better work-life balance. Thereby, importance of family is confirmed once again in empirical studies.
\end{abstract}

Key words: Civil economy, self interest, homo œeconomicus, reciprocity, gratuity, family, transcendent motivation.

\title{
I Parte
}

\section{La economía del don}

\section{La economía del don}

Las crisis externas e internas, que perturban la vida de las personas, las naciones y las regiones de nuestro mundo, nos instan a buscar modelos que superen al del homo œconomicus, aparentemente tan eficaz para impulsar el desarrollo de la producción y del conocimiento durante por lo menos dos siglos. La referencia al homo œconomicus seguramente es fruto de una conocida frase de Adam Smith (1776), que en su fundacional ensayo sobre el origen de las riquezas de las naciones dice: "No es la benevolencia del carnicero, del cervecero o del panadero lo que nos procura el alimento, sino la consideración de su propio interés. No invocamos sus sentimientos humanitarios, sino su egoísmo, ni les hablamos de nuestras necesidades, sino de sus ventajas" (p. 23). 
Es innegable el carácter universal del interés propio como motivo de la acción humana, pero no deja de ser un reduccionismo - y no sin graves consecuencias - el no reconocer otros motivos de la conducta humana, incluso en la producción de bienes o servicios.

Este modelo reduccionista, el único hasta ahora vigente a nivel global, empieza a mostrar efectos adversos tanto en la protección del ambiente como en el cuidado de las personas o la posibilidad de la paz; por eso podemos afirmar que estamos en el umbral de un cambio cultural profundo. De hecho, el mundo del trabajo, estructurado sobre la base de la productividad de un individuo abstractamente autosuficiente, se muestra del todo inadecuado para la vida de las personas y para la formación de las familias. Esto se comprueba por sus efectos en el tejido social: el individualismo está debilitando los lazos sociales y la economía necesita del tejido social para subsistir (Bruni, 2017).

Para estructurar la actividad productiva sobre una base menos abstracta es necesario ampliar la visión hacia la complejidad de las necesidades humanas individuales y sociales. Los seres humanos nacen y se desarrollan en comunidades, es así que muchos de sus talentos solo aparecen en la interacción con los demás. Pensemos en la comunicación, la capacidad de servicio, la solidaridad, la organización, incluso el arte, que si bien puede gestarse en soledad, está claramente destinado a un receptor. Si la sociabilidad humana es un rasgo constitutivo de las personas, su modo de producir, de crear, de distribuir debe tenerla en cuenta.

\section{Algunos antecedentes históricos de la economía del don}

El desarrollo de las distintas teorías económicas ha seguido el paso de la expansión de la industrialización, en la que la producción para el intercambio ha ido reemplazando a aquella solo para el uso. Contemporánea de la Revolución Industrial, se ha afirmado rápidamente la reflexión económica de corte liberal, que se ha manifestado sumamente eficaz para orientar la nueva forma de producción, tanto en la optimización del uso de recursos como en la limitación de riesgos y el impulso a la innovación. Estos aspectos son todavía hoy sumamente apreciados por su eficacia y su dinamismo. Sin embargo, ni bien la Revolución Industrial empezó a expandirse y sumar países, empezaron a verse también los efectos no deseados del nuevo orden, que resultó ser no solo económico, sino también social. Seguramente Karl Marx ha sido una de las voces más sonoras en la crítica de lo que él llamó "economía política”, a la que acusó de ocultar bajo los términos neutros de relaciones económicas las injustas relaciones entre personas (Marx, 1973); pero no fue el único en esta crítica. Pierre-Joseph Proudhon, contemporáneo de Marx - y su inspirador, por lo menos en el concepto de la propiedad privada entendida como robo-, partiendo de un 
supuesto antropológico diferente al del liberalismo, imagina una sociedad basada en la mutualité, es decir, la reciprocidad (Proudhon, 1841). Su estudio de las clases subalternas pareció apuntar a un diseño de sociedad mucho más cooperativa, quizá algo utópica - lo que le valió el repudio de Marx- pero más fecunda y más respetuosa de las diferencias individuales.

En esa misma línea de economía alternativa, hay que leer el aporte de Marcel Mauss, también francés, sobrino de Émile Durkheim, autor en 1924 del Essai sur le Don, en el cual propone una visión no individualista de la actividad productiva humana. La idea del don transforma radicalmente el intercambio entre las personas: la simple transacción dictada por el interés es reemplazada por la dimensión del don, que, en cambio, implica una dinámica de cohesión interpersonal. De los escritos innovadores de Mauss ha surgido el movimiento M.A.U.S.S.: Mouvement Anti-Utilitariste en Sciences Sociales, un verdadero programa de lectura de la sociedad, pero también de acción en la sociedad (Revue du MAUSS, 1994).

Es necesario leer también la crítica de Karl Polanyi (1989) a la categoría de mercado como única ley social, como un paso en ese mismo sentido, aunque desde el estudio de los deletéreos efectos sociales de la extensión de la mentalidad mercantil a todos los intercambios sociales. Según Polanyi, los economistas, después de Adam Smith, han dejado de interesarse por otras formas existentes de economía no de mercado; en estas, la reciprocidad y la redistribución tienen un papel relevante, dado que el interés de las personas no reside solo en las posesiones materiales, sino también en la plena inserción en el grupo. Sin embargo, según Polanyi, la ficción del mercado como regulador no solo de la producción, sino también de las relaciones sociales ha tenido como efecto una distorsión social difícil de eliminar si no se reemplaza la lógica mercantil por una economía de dimensión humana.

\section{La economía del don como humanización}

Según Groppa y Hoevel (2014), "a través de las actividades económicas nos involucramos en relaciones interpersonales con los demás que afectan no solo a nuestra vida y felicidad privadas, sino que influyen también en los niveles de justicia y bien común que existen en la economía y la sociedad". Esta afirmación — respaldada en sólidos estudios (Bruni, 2017), en los que la economía no se desentiende de otras disciplinas, como la sociología, la antropología y la moral- permite plantear un escenario distinto al enrarecido de una economía regida por una cruda racionalidad que solo busque maximizar resultados. Esta visión reduccionista del homo œeconomicus nace de la producción al por mayor de nuevos pobres en todos los continentes, así como justifica el surgimiento y la expansión de conflictos bélicos en las más diversas latitudes, por haberse independizado abusivamente la racio- 
nalidad económica de la sensatez y la justicia. Según Groppa y Hoevel (2014), la economía del don representa un enfoque innovador y fecundo de los temas económicos, permitiendo además apreciar debidamente el efecto social de la actividad económica, dado que lo puramente cuantitativo mal puede definir una actividad humana. La palabra economía está constituida por las palabras griegas oikos (casa) y nomos (ley, regla); esta etimología debería recordarnos que no es posible hablar de economía sin hablar de la persona humana, en la cual —en cuanto persona y no meramente individuo de una especie - los lazos sociales tienen un rol constitutivo. Por esta razón, nos resulta lógico entender que solo una abstracción que ideologiza puede hacernos prescindir de considerar lo económico en su aspecto de actividad humana.

El economista italiano Stefano Zamagni (2013) advierte que en los últimos tiempos la economía ha conseguido, por un lado, colonizar a las otras ciencias sociales y, por otro, "sacar la ética de la reflexión económica", lo cual no puede conducir a buen fin. Uno de los primeros efectos de esta independización de la economía es el desinterés por su efecto en el bien común, dado que se niega la misma existencia de la sociedad sobre la base de la "antropología minimalista del homo œconomicus" y una "metodología del atomismo social". Por otra parte, nos señala el mismo autor que hay evidencias más que firmes respecto de que "en la realidad de nuestras sociedades avanzadas, menos de la mitad de las personas se comportan según el canon del homo œconomicus" (Zamagni, 2014, p. 35), por lo cual, para comprender la realidad y para eventualmente corregir los pasos en falso, no es sensato crear modelos según la mera racionalidad económica. Todo esto se vuelve urgente en el contexto de la globalización, que interviene pesadamente sobre los lazos culturales, sociales y laborales de muchas comunidades, sin proponer otra cosa que la maximización, en un claro desconocimiento de lo humano. Pero hay una reacción frente a esta forma reductiva de interpretar las relaciones humanas: "El espíritu del hombre contemporáneo se rebela y reclama. Hoy, la palabra clave que mejor expresa esta exigencia es la de fraternidad" (Zamagni, 2014, p. 42).

A la luz de esta rebelión oportuna, rebelión en favor de lo humano, entendemos que hay un cambio también en el mundo del trabajo, en la cultura de las empresas, en las exigencias de las personas y en sus expectativas, en aquello que constituye la fuente de satisfacción en el trabajo y en su vida personal. La idea de una economía del don no es más que la vuelta a la comprensión de toda actividad productiva como actividad humana, destinada a responder a las necesidades humanas, pero también capaz de dar forma a buenas relaciones interpersonales. Sin este cuidado no hay desarrollo posible, así como no hay democracia, porque donde se automatizan los motivos de la acción no puede haber compromiso y responsabilidad. La economía del don es una respuesta a los efectos indeseados del mercado como sistema autónomo: la pobreza, la exclusión y la violencia. 
La economía del don es la premisa necesaria para una estructura social capaz de contener y desarrollar a las personas tanto en su individualidad como en su relación con los demás. El don y la reciprocidad, en sus distintos grados, forjan los elementos de la cohesión social y permiten, en última instancia, también los intercambios del mercado, pues este no puede prescindir de una fase de confianza para comenzar a funcionar.

\section{Un cuento navideño: Don y reciprocidad en un peaje de Manhattan}

Esta insistencia en el don y la reciprocidad como condiciones del funcionamiento mismo de la comunidad humana tiene una base empírica importante en la vida de cada uno de nosotros, que no hubiéramos llegado a la edad adulta si no hubiésemos sido objeto de cuidados generosos de parte de otros adultos. No creo que los padres o los adultos en funciones parentales piensen siquiera en la reciprocidad, pero sé que en el seno de la familia la reciprocidad está, por ejemplo, en el núcleo del funcionamiento de las relaciones entre hermanos.

Me permito contar aquí una anécdota de Navidad, acaecida en un peaje de un puente que conecta Manhattan con Jersey City.

Con gran sorpresa, cuando Mr. X pasaba por el peaje con el dinero ya en la mano para pagar, escucha del encargado lo siguiente: “¡Feliz Navidad! Su peaje ha sido pagado por el señor que pasó antes”. Mr. X se sorprendió y al mismo tiempo se alegró enormemente, y sin pensarlo demasiado — en una fila de peaje no hay que perder tiempo- pagó para el siguiente. No gastó más de lo que iba a gastar, pero produjo un beneficio mucho mayor que su gasto. Un beneficio no cuantificable. Esta cadena de favores se repitió por unos cuantos autos más, hasta que alguien, muy poco recíproco o poco rápido para innovar, recibió contento el don, pero interrumpió el flujo.

Analizando la anécdota a la luz de la economía del don y de la reciprocidad, se ve que siempre hace falta alguien totalmente altruista para que la economía del don funcione. En realidad la actitud altruista hace falta, en cierta medida, para que la sociedad funcione. Ese gesto de altruismo navideño recibía su satisfacción del hecho mismo de crear un flujo generoso a su alrededor; su beneficio es incuantificable, pertenece a otra dimensión, a la misma capacidad humana de gozar por el bien. En cuanto al primer beneficiario, su actitud de seguir con la cadena fue una respuesta de reciprocidad al gesto del don; su expectativa no era recibir algo a cambio, pues ya había recibido, sino ser parte de algo bueno. El que interrumpió la cadena razonó rápidamente con la mentalidad del provecho individual, o quizá era simplemente alguien de temperamento muy secundario. 
Esta anécdota permite ver cuántos frutos producen el don y la reciprocidad y cuán estéril puede llegar a ser la lógica de la ganancia material y la ventaja individual.

También ilustra cómo las virtudes necesarias para que la sociedad entera funcione de una manera aceptablemente humana no son el resultado de esa lógica ni de las eventuales palancas materiales, como los distintos incentivos, sino de algo generoso y libre, como deja bien en claro el estudio de Bruni y Grevin (2017).

\section{Parte}

\section{La economía del don como inspiración de work/life balance}

\section{El reconocimiento social del valor de la familia}

Muchas voces diversas se han levantado en el siglo XXI para reconocer el valor social de la familia, como factor de arraigo, identificación y desarrollo de las personas. Tanto Luc Ferry con su Familles, je vous aime (2006) como Gilles Lipovetsky en El crepúsculo del deber (2000) y en numerosas entrevistas recientes, pasando por el estudio de José Pérez Adán Repensar la familia (2005), por nombrar algunos, dan crédito a esta renovada atención al rol social de la familia, justamente en el medio de una cultura que hace más difícil fundar familias duraderas.

También en el informe de CEPAL (2008), en el cual se afirma: "La familia goza de buena salud en la valoración que los jóvenes hacen de ella", pues este es un espacio de apoyo y cariño, donde los conflictos se pueden solucionar con el diálogo. Pero en el estudio de CEPAL, se señala también que hacen falta programas de desarrollo de equidad económica y educativa para que sea posible formar familias.

Como se ve, el foco está puesto en la necesidad de fomentar la formación de familias funcionales y favorecer su vida cotidiana como un medio concreto para aportar a la salud social en su totalidad.

En su estudio sobre la familia en Latinoamérica titulado Los desafíos éticos abiertos en un continente paradójico, dice Bernardo Kliksberg (2007): "[La familia] sigue constituyendo la unidad esencial para los jóvenes. Múltiples investigaciones recientes han corroborado su peso fundamental en la afectividad, la salud psíquica, el equilibrio emocional, la madurez, la inteligencia emocional, la capacidad de aprendizaje y otras áreas claves".

Este valor insustituible de la familia se origina debido a que, aun en una cultura como la actual, marcadamente individualista y reacia a los compromisos, la realidad familiar constituye el ámbito en el que vive la mayoría de los jóvenes lati- 
noamericanos: la familia nuclear representa todavía el $58 \%$ en la región, y junto con la familia extendida representan el $91 \%$ de todas las familias (Kliksberg, 2007). Asimismo, este autor refiere que cerca del 8o \% de los jóvenes de Chile, México y Colombia viven con su familia de origen. En Argentina, el último censo del INDEC (Instituto Nacional de Estadística y Censos) de 2010 consignó la presencia de 12 millones de hogares, con un aumento de 2 millones respecto del año anterior; si bien no es lo mismo hogar que familia, en la realidad argentina la familia —es decir, una unión de personas formalizada y jerarquizada - sigue siendo mayoritaria, el $61 \%$ aproximadamente, pero con un considerable aumento de las uniones consensuales y la correspondiente disminución de la nupcialidad, más notoria en los más jóvenes.

Ahora, cuando se constata que las conductas de riesgo de los jóvenes — desórdenes alimenticios, deserción escolar, adicciones, embarazos adolescentes, pandillas, pobreza, delincuencia, etc. - tienen siempre una fuerte conexión con una familia ausente o disfuncional (Pérez, 2005), se ve con más claridad la urgencia de que todas las entidades de la sociedad se preocupen por desarrollar en sus miembros la capacidad de formar buenas familias y por favorecer la vida familiar como un aporte sustancial para una sociedad sana, pensando especialmente en sus miembros más vulnerables.

\section{La vida en familia como clave para la satisfacción de vida}

Por otra parte, estudios empíricos (Bjarnason et al., 2012) sobre niños y adolescentes de 36 países muestran que la vida satisfactoria de la nueva generación está en directa relación con la presencia de su familia biológica intacta, y disminuye progresivamente con las formas familiares más alejadas de su estructura inicial. La investigación de Bjarnason et al. (2012) consigna una interesante correspondencia entre la presencia de la familia intacta - eso es la familia biológica de los niños y los adolescentes entrevistados - y el grado de satisfacción de vida, entendido en una escala entre el peor modo de vida y el mejor, incluyendo la posibilidad de una buena comunicación, de medios de vida aceptables, etc. Los resultados son claros respecto de la ventaja que representa vivir en la familia de origen, a pesar de que a causa de supuestos politizados en contra de la así llamada familia tradicional no se pueda obtener más inspiración para, por ejemplo, diseñar políticas públicas de fomento y protección de la familia.

Sin embargo, los resultados son contundentes:

Los niños que viven con ambos padres biológicos reportaron niveles más altos de satisfacción de vida que los niños que viven solo con uno de los padres, o con la madre y el padrastro o el padre y la madrastra. Los niños que son cuidados por ambos padres, 
aunque separados, han reportado niveles más altos de satisfacción de vida que sus pares en otros tipos de familias no intactas ${ }^{3}$ (Bjarnason et al., 2012, p. 52).

Con esto no se quiere emitir ninguna condena a nadie, sino llamar la atención respecto del valor social de la familia como lugar oportuno para recibir la vida nueva, cuidarla y prepararla para la adultez en un clima de aceptación, reconocimiento y estímulo. En esta investigación, cuanto más se aleja la familia de la estructura fundante, tanto menos es la satisfacción de vida de los niños y los adolescentes; en ese mismo sentido, se aprecia un nivel muy bueno de satisfacción de vida cuando, en la situación de separación de los padres, ambos se hacen cargo concretamente del cuidado de los hijos.

\section{El cambio de la cultura y el rol de las personas con cargos directivos}

Estas evidencias deberían inspirar a las personas a cuidar su vida familiar y a no perseguir altos resultados económicos o de carrera a costa de la integridad familiar: sería un precio personal demasiado alto y sería un empobrecimiento social de incalculable dimensión.

Si nos preguntamos si es posible alinear la propia profesión a una vida personal y familiar satisfactoria, viene a la mente la interesantísima distinción de tres tipos de motivaciones para el trabajo que nos legó José Antonio Pérez López (2002), maestro de numerosísimos directivos de empresa y de profesores de escuelas de negocios, recordado siempre con admiración y afecto por todos los que tuvieron la dicha de frecuentarlo. Preocupado siempre por la humanización de la tarea directiva y por la conquista de la dimensión ética del trabajo de los empresarios - varones y mujeres- distinguió entre la motivación extrínseca, la motivación intrínseca y la trascendente.

Según el autor antes mencionado, la primera, la motivación extrínseca, es la de los que trabajan exclusivamente (o prioritariamente) movidos por un resultado en cierto sentido externo respecto del trabajo mismo, como la compensación económica o el ascenso en la carrera. La motivación intrínseca, en cambio, pone el acento en el crecimiento personal, como, por ejemplo, el desarrollo y el reconocimiento de las propias capacidades; finalmente, la motivación trascendente hace foco en el efecto benéfico del propio trabajo en los demás: uno trabaja porque percibe que eso es bueno también para otros, es un aporte al bien común, construye la comunidad. Por eso, uno disfruta cuando percibe esos resultados positivos en la vida de los demás.

3 Traducción propia. 
Es claro que esta última motivación está en línea con la idea de la economía del don y es bajo esta luz que analizaremos los resultados de una encuesta llevada a cabo por el centro CONFyE (Conciliación Familia y Empresa) del IAE (Business School-Universidad Austral) durante el 2013. Esta investigación, realizada en Argentina a través de un cuestionario autogestionado al que respondieron 868 directivos de empresa y mandos medios - varones y mujeres-, muestra que las personas que manifiestan una motivación trascendente para el trabajo, a diferencia de quienes están motivados de forma extrínseca o intrínseca, buscan constantemente armonizar su trabajo con su vida familiar y aportar al bien de los demás, poniéndose en línea con los criterios de la economía del don o de la reciprocidad. Estos datos son un aliciente para que las empresas acepten su rol de educadoras y constructoras de la sociedad, entre otras organizaciones. Algunos de sus principales resultados son mostrados a continuación:

En la Figura 1, se comparan los resultados según la motivación y de acuerdo con diversas preguntas. En la primera serie, se preguntó si trabajaban para obtener recursos materiales, y las respuestas fueron afirmativas en el $82 \%$ de los de motivación extrínseca, el $76 \%$ de los de motivación intrínseca y el $60 \%$ de los de motivación trascendente. Está claro que es necesario que el trabajo sea compensado con un sueldo, pero los trascendentes manifiestan que hay algo más en juego que la simple compensación económica. En la segunda serie, le asignan mucha importancia a la posición económica alcanzada como muestra de éxito profesional el $82 \%$ de los extrínsecos, el $75 \%$ de los intrínsecos y el $60 \%$ de los trascendentes, confirmando la tendencia de la anterior pregunta.

Figura 1.

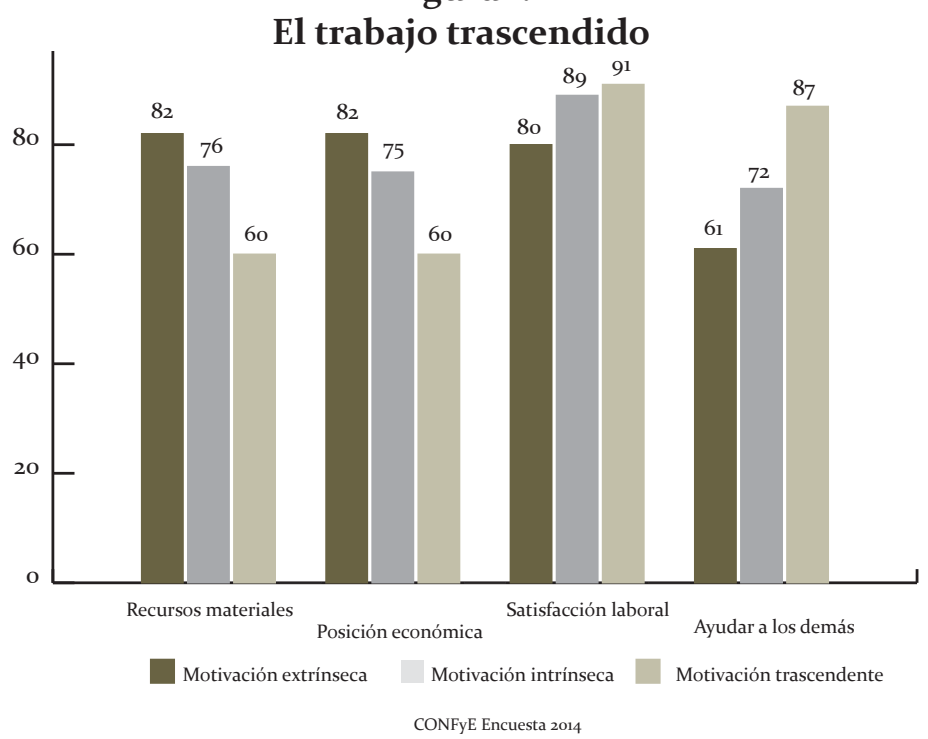


En la tercera serie, afirman estar satisfechos con su trabajo el 8o \% de los extrínsecos, el $89 \%$ de los intrínsecos y el $91 \%$ de los trascendentes, evidenciando que el menor interés por la compensación no indica falta de dedicación o de satisfacción en el trabajo, sino todo lo contrario. En la cuarta serie, contestan que el éxito de la carrera implica poder ayudar a los demás el 61\% de los extrínsecos, el $72 \%$ de los intrínsecos y el $86 \%$ de los trascendentes. Llama la atención que, a pesar de ser pequeñas diferencias, se va delineando perfectamente el perfil de los que tienen motivación trascendente como los que van más allá del sentido puramente instrumental de su trabajo, y por eso mismo encuentran más satisfacción en lo que hacen y tienen una mayor propensión a considerar su trabajo como un aporte a los demás.

La primera serie de la Figura 2 muestra un alto grado de satisfacción laboral para las tres motivaciones: les gusta lo que hacen al $96.9 \%$ de los extrínsecos, al $97.8 \%$ de los intrínsecos y al $98.3 \%$ de los trascendentes. En suma, todos aman su trabajo y están satisfechos, y no es eso lo que establece la diferencia al interior de este grupo de directivos. En la segunda serie, afirman que es posible el equilibrio entre profesión y vida familiar el $74 \%$ de los extrínsecos, el $79 \%$ de los intrínsecos y el $86 \%$ de los trascendentes. De nuevo, se confirma la actitud de conciliación más marcada en los directivos de motivación trascendente. En la tercera serie, afirman que el trabajo es exitoso cuando permite el propio crecimiento y el de otros el $83 \%$ de los extrínsecos, el $94 \%$ de los intrínsecos y el $98 \%$ de los trascendentes. En este punto, y con este resultado, creo poder afirmar que la motivación trascendente es la que más se acerca a la economía del don. En la cuarta serie, afirman que es posible tener a la vez una profesión exitosa y una vida familiar plena el $74 \%$ de los extrínsecos, el $79 \%$ de los intrínsecos y el $86 \%$ de los trascendentes. Sorprende el hecho de que la conciliación entre trabajo y familia ya no parece algo inalcanzable, sino que un porcentaje importante de los directivos y los mandos medios encuestados considera posible tener a la vez ambos aspectos de la vida en un nivel muy bueno; nuevamente, vemos una ventaja constante en los que trabajan con motivación trascendente. 
Figura 2.

Integración personal

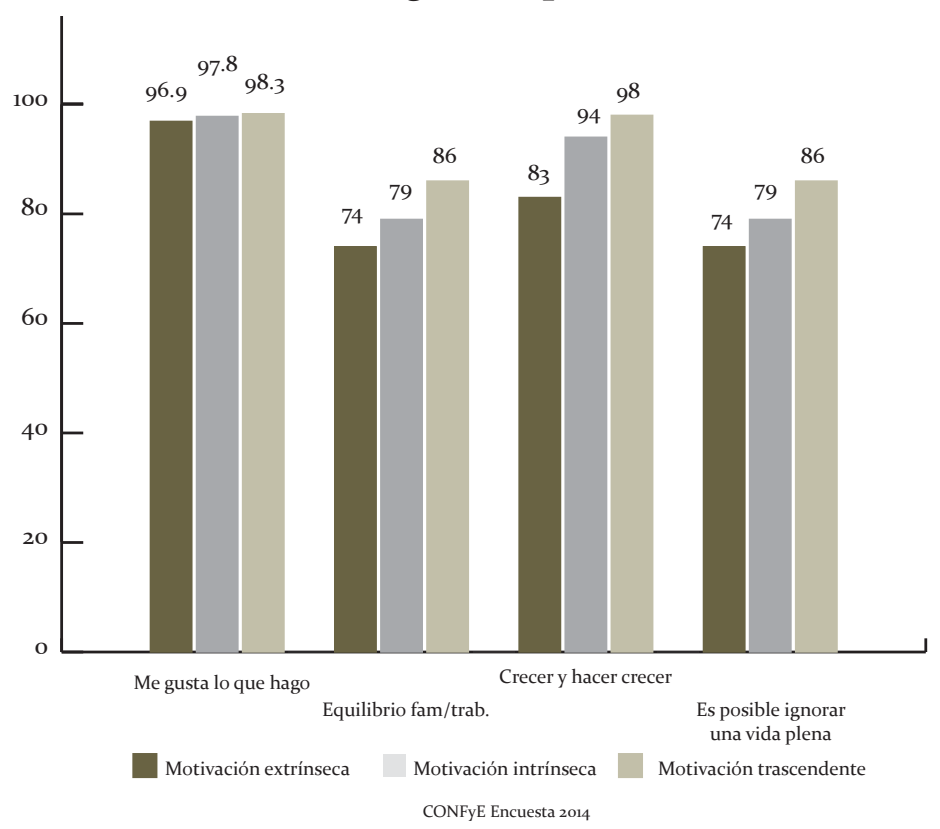

Por último, en la Figura 3 analizamos la disposición a ser proactivos para obtener una mejora en la conciliación trabajo/familia en la empresa. En esta tercera figura, vemos en la primera serie que la propensión a buscar tiempo para planificar el trabajo es del $30 \%$ de los extrínsecos, el $33 \%$ de los intrínsecos y el $41 \%$ de los trascendentes; en la segunda serie, afirman que en su organización se podría hacer más para obtener conciliación el $47 \%$ de los extrínsecos, el 6o \% de los intrínsecos y el $69 \%$ de los trascendentes, que una vez más muestran una mayor disposición para un cambio positivo. En la tercera serie, se analiza la cultura de la empresa, así que el $34 \%$ de los extrínsecos, el $47 \%$ de los intrínsecos y el $56 \%$ de los trascendentes afirman que en su compañía está bien visto el preservar un tiempo para la familia. Finalmente, en la última serie, el $48 \%$ de los extrínsecos, el $52 \%$ de los intrínsecos y el $56 \%$ de los trascendentes afirman que tienen proyectos con sus hijos. De nuevo, notamos que es constante la ventaja de los que trabajan con una motivación trascendente en el sentido de la conciliación activa, y que se disponen por lo tanto a trabajar en pos de una cultura de mayor integración de los distintos aspectos de la vida de una persona. Estos resultados indican que ha empezado un cambio, y que este cambio viene afirmándose poco a poco pero constantemente. Además, resulta 
bastante evidente que la motivación trascendente es la que más aporta para renovar la cultura laboral, porque es propia de las personas que ven su trabajo no solo como la fuente de sus recursos económicos, sino también como un aporte al desarrollo humano, corrigiendo el economicismo, que a menudo domina el ámbito empresarial, por una cultura más integrada.

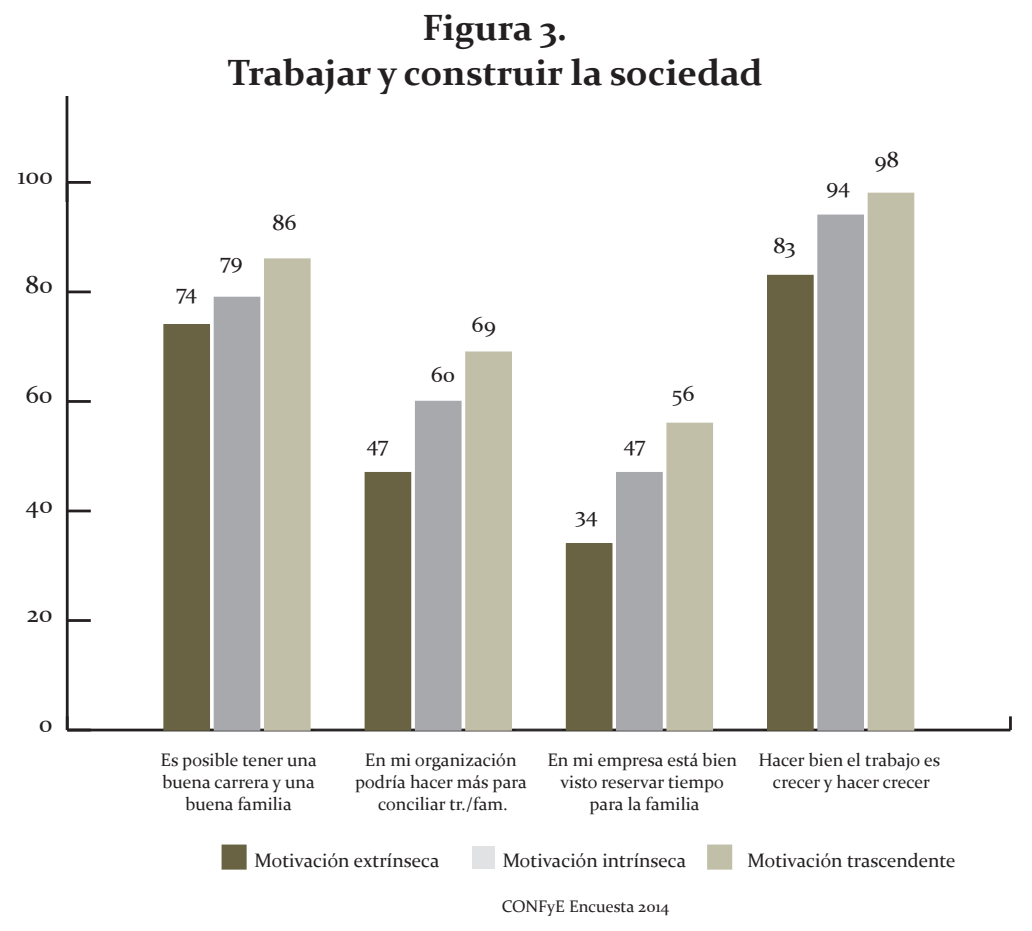

Para las personas preparadas y responsables, que aman su profesión, aman a sus seres queridos y necesitan además otras actividades para superar el estrés producido por tantos frentes de batalla, una cultura de integración representa realmente una solución.

\section{Las empresas también construyen la sociedad}

Hoy en día, a pasos pequeños a veces y a grandes otras, nos encontramos frente a un renovado escenario, en el cual las empresas, siendo ámbitos en los que se completa la educación de los adultos, se ven cada vez más impulsadas a aceptar su papel de constructoras de la sociedad, lógicamente, junto con otras entidades. ¿Qué quiere decir que la empresa construye la sociedad? Que acepta que muchos cambios ne- 
cesarios para el buen funcionamiento social dependen en gran medida de lo que su cultura fomente entre sus colaboradores. Y como estamos hablando de cultura, no se tratará exclusivamente de proveerles a los colaboradores las herramientas que los hagan más eficientes y eficaces, sino que el objetivo se centra en el crecimiento de las personas como tales. ¿Es mucho pedir? Sí, pero ya está ocurriendo.

Algunos motivos: las empresas, en el esfuerzo de resultar atractivas para las nuevas generaciones - que han entendido por el estrés de sus padres y madres que no hay que entregarle la vida entera al trabajo-, se están preocupando por ofrecer un espacio laboral más humano, más amigable, más compatible con las múltiples necesidades de las personas, que no se sienten satisfechas únicamente por la compensación económica (Bruni, 2017). Si esta es alta, resulta atractiva en un primer momento; pero su atractivo se erosiona rápidamente cuando otras necesidades quedan crónicamente desatendidas. Me refiero, por ejemplo, a la necesidad de cohesión con el grupo, de espacios de comunicación tanto para la expresión como para la escucha, de comprensión empática, de valoración de lo que uno hace; a la captación del sentido del propio esfuerzo en el contexto del esfuerzo de los demás (Delbosco \& Paladino, 2010).

A la preocupación de las empresas por establecer un ámbito propicio para el desarrollo personal y grupal de su gente debiera corresponderle el compromiso personal de cada colaborador a través de la idoneidad y la dedicación; así también, la sociedad debiera tener un mensaje claro respecto de las necesidades humanas, individuales y grupales que hay que atender.

En etapas progresivas, se ha operado un cambio de mentalidad por el cual en vez de deslindar drásticamente los diferentes campos de presencia y actividad de las personas se busca integrar la realidad laboral y la familiar, lo recreativo y lo solidario, lo personal y lo grupal.

Muchas razones están en la base de esta modificación, que, si se hace bien, traerá un gran alivio a quienes frenéticamente pasan de un ámbito al otro, tratando de dar lo mejor de sí y trayendo como efecto indeseado la inevitable sensación de no estar dando nunca lo suficiente.

La economía del don y el concepto de reciprocidad favorecen esta integración, así como lo hacen las personas movidas por la motivación trascendente: el resultado de este enfoque más humano de la actividad productiva, liberada de la ficción del homo œconomicus, permite albergar fundadas esperanzas en el surgimiento de una sociedad más cooperativa y más generosa (Zamagni, 2014). 
Me gustaría cerrar este ensayo con la idea de que el cambio dependerá, como nos dicen Bruni y Grevin (2017), de "una visión del hombre como una persona, un ser de relaciones, capaz de dar, capaz de gratuidad, de grandes ideales, en busca permanente de sentido, de justicia, de bien, de belleza, sediento de encuentros, de estima, de confianza, de amistad, de fraternidad, de reciprocidad" (p. 197).

Sobre esa antropología resulta claro que la economía del don es fruto de toda la persona, y es la única fuente de la que brotan las actitudes necesarias para la vida social: la confianza, la gratitud, la generosidad; así podemos afirmar que la economía del don es la base práctica y realista para una sociedad más humana.

\section{Referencias}

Bruni, L., \& Grevin, A. (2017). La economía silenciosa. Buenos Aires: Ciudad Nueva. Bjarnason, T., Bendtsen, P., Arnarsson, A. M., Borup, I., Iannotti, R. J., Löfstedt, P., ... Niclasen, B. (2012). Life Satisfaction among Children in Different Family Structures: A Comparative Study of 36 Western Societies. Children $\mathcal{E}$ Society, 26, 51-62.

CEPAL. (2008). Juventud y Cohesión Social en Iberoamérica: un modelo para armar. Santiago de Chile: CEPAL. División de Desarrollo Social.

Ferri, L. (2008). Familia y amor. Un alegato a favor de la vida privada. Buenos Aires: Taurus.

Fraile, G., \& Delbosco, P. (2010). El desafío de cada día. Buenos Aires: IAE Press. Fraile, G. (2017). ¿Por qué trabajas tanto? Buenos Aires: Mil Palabras.

Groppa, O., \& Hoevel, C. (2014). Economía del don: Perspectivas para Latinoamérica. Buenos Aires: Ciudad Nueva.

Kliksberg, B., \& Sen, A. (2007). Primero la gente: Una mirada desde la ética del desarrollo a los principales problemas del mundo globalizado (11. ${ }^{\mathrm{a}}$ ed.). Barcelona: Planeta.

Kube, S., Maréchal, M., \& Puppe, C. (2012). The Currency of Reciprocity: Gift Exchange in the Workplace. American Economic Review, 102(4), 1644-1662.

Lipovetsky, G. (2000). El crepúsculo del deber (5. ${ }^{\mathrm{a}}$ ed.). Barcelona: Anagrama.

Marx, K. (1973). Il capitale. Roma: Riuniti.

Paladino, M., \& Delbosco, P. (2010). Dar sentido a la empresa. Buenos Aires: Temas. Pérez, A. (2005). Repensar la familia. Madrid: EUNSA.

Pérez, J. (2002). Fundamentos de la dirección de empresas. Madrid: Rialp.

Polanyi, K. (1944). La gran transformación. Madrid: La Piqueta.

Proudhon, P. (1840). Mémoire sur la Proprieté. Paris: César Bajat.

Revue du MAUSS. (1994). Pour une autre économie, 3. Paris: Revue du MAUSS. Smith, A. (1776). An Inquiry into the Nature and Causes of the Wealth of Nations. Londres: W. Strahan \& T. Cadell. 
Zamagni, S. (2009). Lecciones de una crisis anunciada. Ensayos de política económica, 2, 6-25.

Zamagni, S. (2013). Por una economía del bien común. Buenos Aires: Ciudad Nueva. Zamagni, S. (2014). Bienes comunes y bien común. En O. Groppa \& C. Hoevel (Eds.), Economía del don: Perspectivas para Latinoamérica (pp. 35 y 42). Buenos Aires: Ciudad Nueva. 